\title{
IMPACT OF ORAL CONTRACEPTIVES ON THE PERIODONTIUM: A HISTOLOGICAL STUDY
}

\author{
Heba A. Shawky*
}

\begin{abstract}
Background: Sex hormones play an important role in periodontal tissue integration. Oral hormonal contraceptive pills (OCPs) were developed over 50 years ago. Different studies reported higher progression rate of gingival inflammation in females using OCPs. The present study was performed to evaluate histologically the influence of oral contraceptives on periodontal tissues.

Materials and Methods: A total of thirty healthy female Wistar albino rats aging between 10 to 12 weeks and weighing $230-260$ gm were enrolled in this study. The animals were divided into two groups, fifteen rats each. Group I (Control group), rats receiving no medication. Group II (Study group), rats received Microcept ${ }^{\circledR}$ monophasic combined oral contraceptive tablets for 36 days. Histological examination of the peridontium was accomplished using light microscopy.

Results: Light microscopic examination of the control group revealed that the gingival epithelium was parakeratinized stratified squamous epithelium with long pointed rete pegs. Pyknotic nuclei were seen in the keratinous layer. Concerning the study group, the gingival epithelium revealed orthokeratinzed stratified squamous epithelium with short and blunt rete pegs and absence of nuclei in keratinous layer. Dentin and cementum showed external resorption.
\end{abstract}

Conclusion: The current study showed that oral contraceptives exhibited histological changes on the periodontium which can be correlated to different clinical findings.

KEY WORDS: Oral contraceptives, orthokeratinized, parakeratinized, periodontium.

\section{INTRODUCTION}

Hormones are specific chemical substances produced by special glands in the body and have potent influence on the development and regulation of the cells and organs..$^{[1]}$ The periodontium is greatly affected by various types of hormones particularly sex hormones. Sex hormones play a crucial role on periodontal tissue integrity, bone turnover, wound healing and progression of periodontal disease. ${ }^{[2]}$ Estrogen and progesterone are the main sex hormones affecting the periodontal tissues. They affect cell proliferation and differentiation of the epithelial tissue as well as the synthesis of collagen fibers in the connective

* Lecturer of Oral Medicine and Periodontology, Oral Medicine and Periodontics Department, Faculty of Dentistry, Pharos University in Alexandria, Egypt. 
tissue. ${ }^{[3]}$ Sex steroid hormones have marked influence on reparative capacity of the periodontal tissues. Sex hormones are known to up-regulate folate metabolism required for tissue maintenance, causing its depletion which in turn inhibits tissue repair. ${ }^{[4]}$ Mariotti $^{[5]}$ reported that estradiol can induce cellular proliferation including keratinocytes and fibroblasts. Furthermore, estradiol was demonstrated to induce marked reduction in collagen and non-collagen protein synthesis by fibroblasts in the gingival tissues and in the periodontal ligament (PDL).${ }^{[6]}$ In addition, progesterone has been proved to increase vascular permeability and proliferation and to increase inflammatory cell infiltration. ${ }^{[7]} \mathrm{On}$ the other hand, estrogen exerted direct effect on PDL cell function through estrogen receptor beta (ERbeta) found on human PDL cells. ${ }^{[8]}$ Thus, variation in the level of sex steroid hormone at different lifetimes (puberty, pregnancy and postmenopausal stage) has an important impact on inflammatory response of periodontal tissues and consequently on periodontal pathogenesis..$^{[9,10]}$

Oral hormonal contraceptive pills (OCPs) were developed over 50 years ago. Their main action is through the prevention of ovulation thus maintaining effective immediate reversible contraception. ${ }^{[11]}$ There are two types of OCPs, the combined oral contraceptive pills (COCP); containing estrogen and progestogen and the progestogenonly pills (POP) which contain only synthetic progestogen without estrogen. ${ }^{[12]}$ Lack of estrogen, allows the POP to be associated with a lower risk of heart diseases and blood clotting compared to the COCP. ${ }^{[13]}$ Clinically, positive correlation was demonstrated between hormonal contraceptives intake and periodontal disease progression. ${ }^{[14]}$ Different studies ${ }^{[15,16]}$ reported higher progression rate of gingival inflammation and increased prevalence of gingival enlargement and clinical attachment loss with women taking oral contraceptives.
The aim of this study was to evaluate histologically the effects of oral contraceptives on periodontal tissues.

\section{MATERIALS AND METHODS}

A total of thirty healthy female Wistar albino rats aging between 10 to 12 weeks and weighing $230-$ $260 \mathrm{gm}$, were obtained from the animal house of Medical Research Institute, Alexandria University. Animals were kept in the animal house of Pharos University and were maintained under controlled conditions of temperature $\left(24 \pm 2{ }^{\circ} \mathrm{C}\right)$, light-dark periods of 12 hours and with free access to water and commercial diet. The international guiding principles for biomedical research involving animals were adopted. ${ }^{[17]}$ The animals were given a four-week adaptation period after they were placed in their new environment. The present research was previously approved by the Ethics Review Board of Faculty of Dentistry, Pharos University.

The animals were divided into two groups, fifteen rats each.

- Group I (Control group): Rats receiving no medication.

- Group II (Study group): Rats receiving Microcept ${ }^{\circledR *}$ monophasic combined oral contraceptive tablets $(0.03 \mathrm{mg}$ ethinyl estradiol and 0.15 mg levonorgestrel) once daily through a gastric catheter after being dissolved in one $\mathrm{mL}$ distilled water. A dose corresponding to $0.12 \mathrm{mg} /$ $\mathrm{kg}$ ethinyl estradiol and $0.6 \mathrm{mg} / \mathrm{kg}$ levonogestrel was given to rats weighing 250 grams. ${ }^{[18]}$ The COCPs was given in 5-day cycles (4-day treatment with 1-day break) for 36 days (9 estrous cycles). ${ }^{[19]}$

By the end of the study period, all rats were sacrificed by an overdose intra-peritoneal injection of $100 \mathrm{mg} / \mathrm{kg}$ Phenobarbital sodium**. Histological examination of the periodontium was accomplished

* Chemical Industries Development Company (CID Co.), Egypt.

** West Ward Pharm., USA 
using light microscopy. Specimens were taken from the mandibular molar area including the tooth with its surrounding periodontium. Buccolingual sections were dissected. The sections were fixed in $10 \%$ neutral buffered formalin for 48 hours. The samples were decalcified, washed under tap water in ascending concentrations of alcohol and embedded in paraffin wax using conventional procedures. Serial sections of $5 \mu \mathrm{m}$ thick were cut using microtome. Sections were mounted on glass slides. Slides were floated on a $40^{\circ} \mathrm{C}$ water bath containing distilled water. Before dewaxing, the slides were placed in a $55^{\circ} \mathrm{C}$ oven for 10 minutes to melt the paraffin. Slides were then deparaffinized in xylene for $3 \times 5$ minutes ( 3 times 5 minutes each).Then slides were hydrated in graded series of ethanol (100\%- 95\%$95 \%-80 \%$ ) for 3 minutes each and then immersed in tap water for 5 minutes. Slides were then stained using Hematoxylin and Eosin stain according to the conventional method for routine histological examination using light microscope. ${ }^{[20]}$

\section{RESULTS}

Light microscopic examination of the control group revealed that the dentogingival junction (DGJ) consisted of keratinized gingival epithelium, non-keratinized sulcular and junctional epithelium. Dentin and cementum showed no signs of resorption (Fig. 1). The gingival epithelium showed parakeratinized stratified squamous epithelium with long pointed rete pegs. The keratinous layer exhibited pyknotic nuclei (Fig. 2). The papillary layer of the lamina propria showed loose fibers arrangement while the reticular layer showed dense collagen arrangement (Fig. 3). The connective tissue layer showed abundance of blood vessels disseminated under the DGJ epithelia (Fig. 4).

Regarding the study group, DGJ epithelia consisted of keratinized gingival epithelium, nonkeratinized sulcular and junctional epithelium. Dentin and cementum showed external resorption, with abundant inflammatory cells and histocytes along the root apex (Fig. 5). Gingival epithelium revealed orthokeratinzed stratified squamous epithelium with absence of nuclei in the keratinous layer. The rete pegs were short and blunt (Fig. 6). Gingival epithelium exhibited large prickle cells, granular layer covered by thin keratinous layer. Loosely arranged collagen fibers were seen in the reticular layer of lamina propria with numerous inflammatory cell infiltrate (Fig. 7).

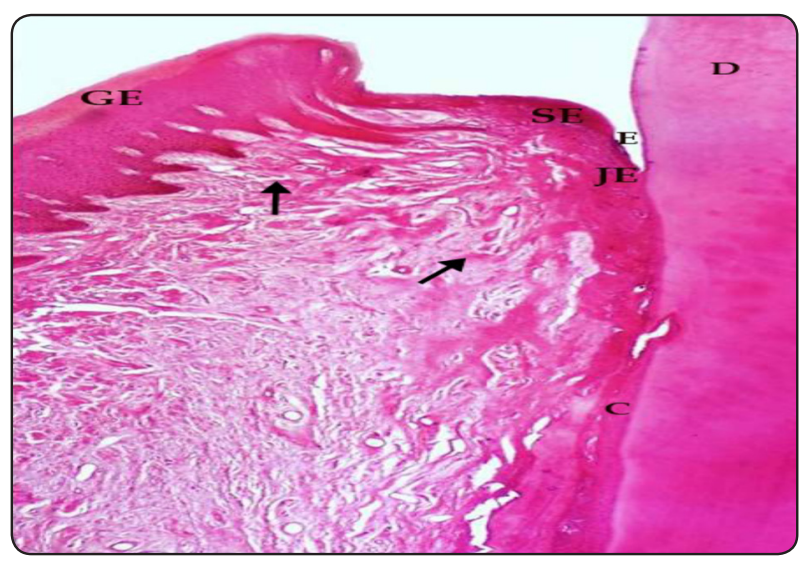

Fig. (1) A photomicrograph of the control group molars showing: Dentogingival Junction epithelia \{keratinized gingival epithelium with long rete pegs (GE), non-keratinized sulcular epithelium (SE) and junctional epithelium (JE)\}, cementum (C), dentin (D), and enamel space $(\mathrm{E})$. Note the dense collagen fibers within the reticular layer of the lamina propria (arrows). (H\&E stain, Orig Mag x40)

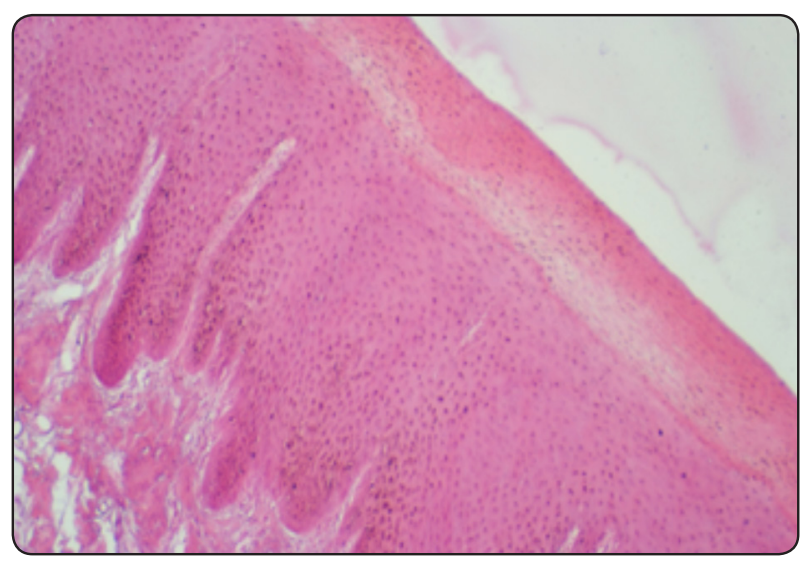

Fig. (2) A photomicrograph of control group gingival epithelium showing: Parakeratinized stratified squamous epithelium (basal cell layer, prickle cell layer, granular cell layer, and parakeratinous layer with pyknotic nuclei) with long pointed rete pegs. The lamina propria showing normal fibers arrangement. (H\&E stain, Orig Mag x 100). 


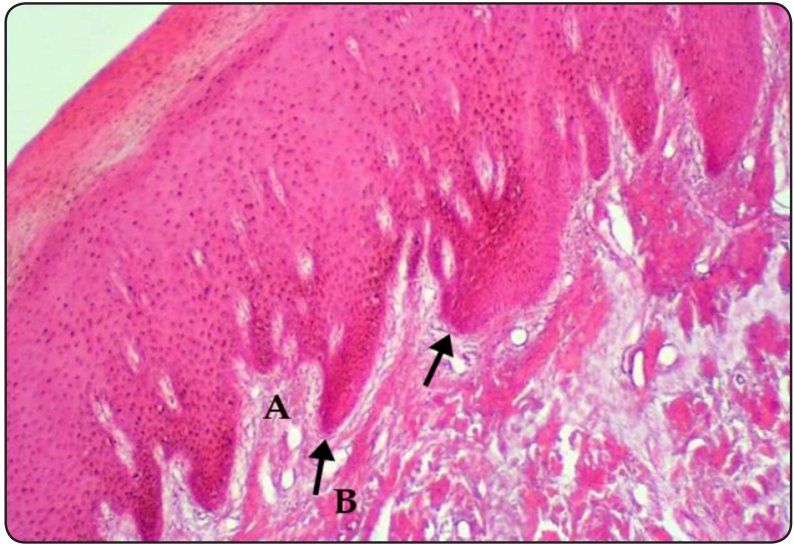

Fig. (3) A photomicrograph of gingival epithelium showing: Parakeratinized stratified squamous epithelium (basal cell layer, prickle cell layer, granular cell layer, and parakeratinous layer with pyknotic nuclei) with long pointed rete pegs (arrows). Note: the lamina propria showing loose fibers arrangement in the papillary layer (A) and dense arrangement in the reticular layer (B). (H\&E stain, Orig Mag x 100)

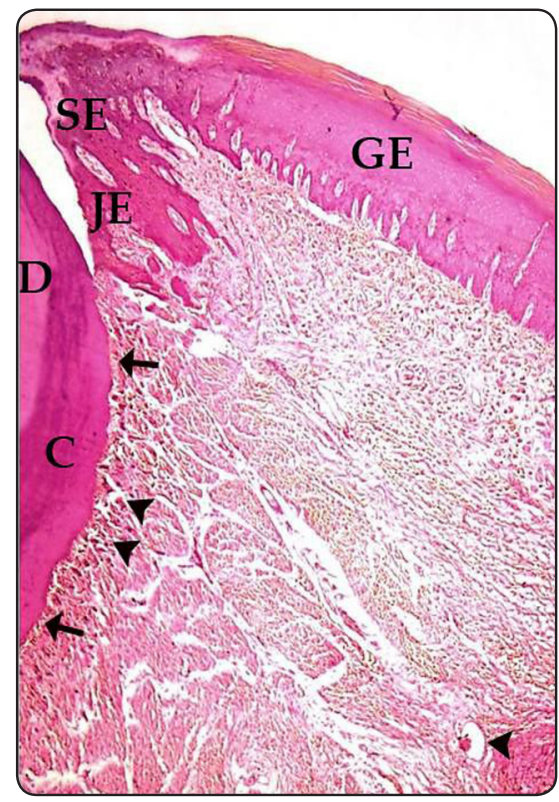

Fig. (5) A photomicrograph of the study group showing: Dentogingival junction epithelia \{keratinized gingival epithelium (GE), sulcular epithelium (SE) and junctional epithelium $(\mathrm{JE})\}$, collagen fibers within the lamina propria (LP), external resorption of cementum surface (C) (arrows) and dentin (D). Note: inflammatory cells and histocytes are infiltrated along the apex of the root (arrow heads). (H\&E stain, Orig Mag x40)

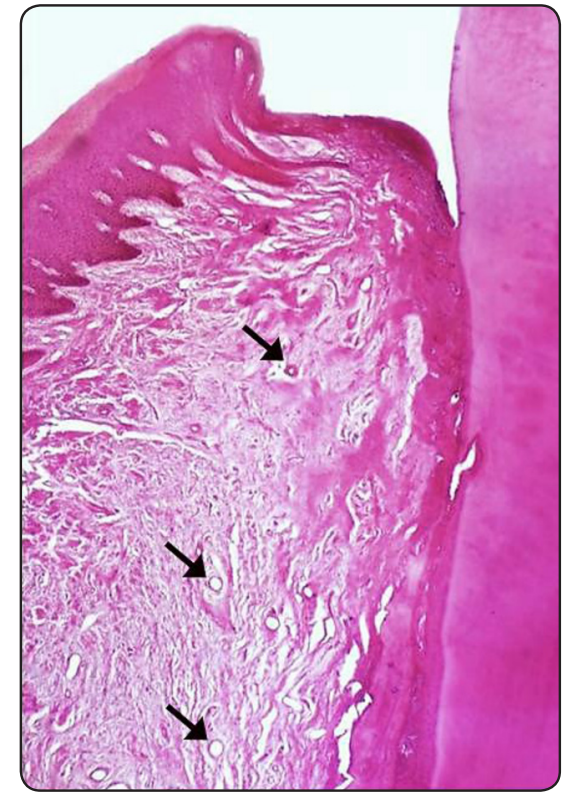

Fig. (4) A photomicrograph of control group showing: numerous blood vessels distributed under the entire surface of the epithelia of DGJ (arrows). (H\&E stain, Orig Mag x40)

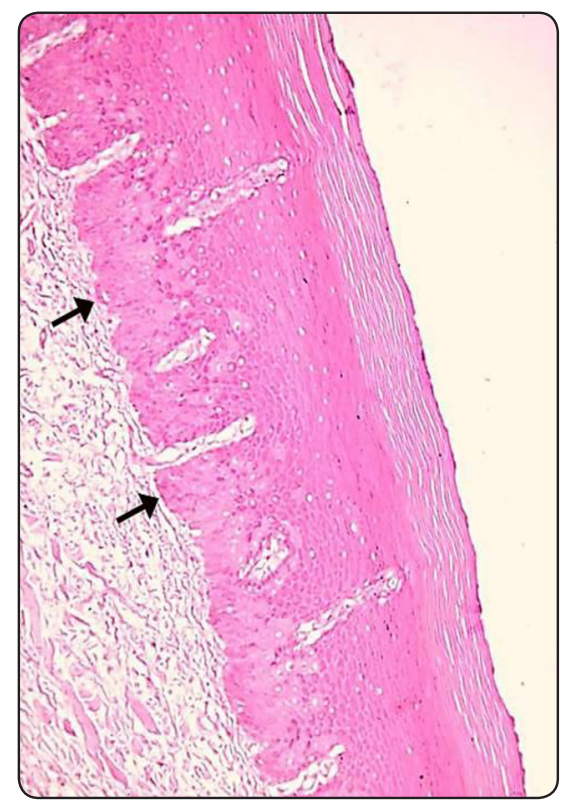

Fig. (6) A photomicrograph of study group gingival epithelium showing: Orthokeratinized gingival epithelium formed of four layers (basal, prickle, granular and keratinous layer with no nuclei). Note: the blunt rete pegs (arrows) with loose papillary layer of the lamina propria. (H\&E stain, Orig Mag x100) 


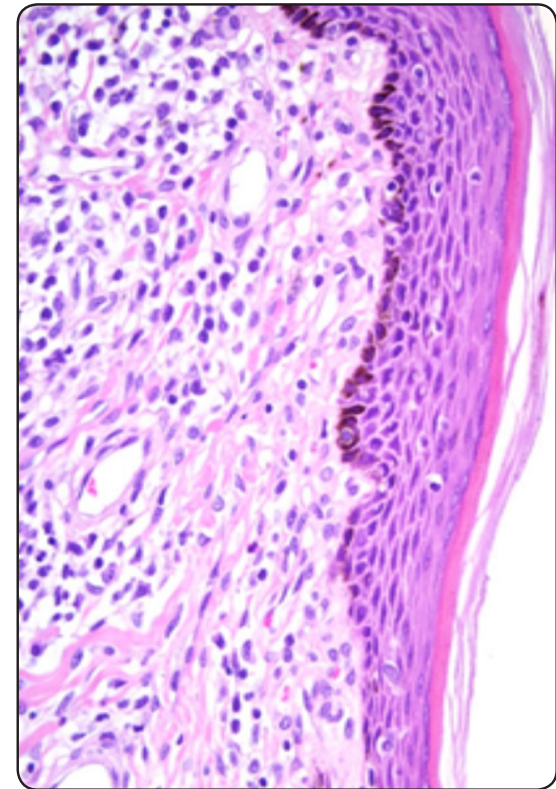

Fig. (7) A photomicrograph of study group of gingival epithelium showing: keratinized stratified squamous epithelium (basal cell layer with relatively large prickle cell layer, granular cell layer, and thin keratinous layer) with short and flat rete pegs. The lamina propria showing loosely arranged collagen fibers with many inflammatory cells. (H\&E stain, Orig Mag x100).

\section{DISCUSSION}

The present study was performed to evaluate the effects of contraceptives on the periodontium. Histological examination of DGJ of the control group revealed three types of epithelia; parakeratinized gingival epithelium, non-keratinized sulcular epithelium and junctional epithelium. The parakeratinized pattern of the gingival epithelium provides a tough surface for protection against hard food particles. This finding is in agreement with Hennet ${ }^{[21]}$ who mentioned that normally the dentogingival junction epithelium consists of three functional compartment gingival, sulcular and junctional epithelium. The gingival epitheliumconnective tissue interface of the control group showed long pointed rete pegs deeply extended into the underlying lamina propria. The connective tissue also showed densely arranged thick bundles of collagen fibers in the reticular layer for the mucoperiosteal junction to render the gingival mucosa immobile and firm.

The sulcular epithelium was non-keratinized stratified squamous epithelium, the surface layer of this epithelium consisted of flat cells containing nuclei forming flexible surface tolerant to compression. In convenience, Laugerette et al ${ }^{[22]}$ demonstrated that the sulcular epithelium normally shows a non-keratinized pattern consisting of basal, prickle, intermediate and superficial layer.

The junctional epithelium was formed of nonkeratinized stratified squamous epithelium consisting of basal cell layer covered by several layers of flat undifferentiated cells lying parallel to the tooth surface promoting the junction between the gingiva and the tooth. This finding is supported by Bartold et $a l,{ }^{[23]}$ as they proved that the junctional epithelium has a major role in providing attachment of the gingival tissue to the tooth, thus its integrity is essential for maintaining healthy periodontium. Periodontal disease occurs when the structure of the junctional epithelium starts to change. ${ }^{[24]}$ Moreover, the connective tissue interface of the junctional epithelium was smooth with no rete pegs, associated with deep connective tissue and showing little capacity to proliferate. Inflammatory cell infiltration was also observed in the connective tissue; the inflammatory cells continually migrate into the junction epithelium and pass between the epithelial cells. In agreement with Nanci and Bosshardt ${ }^{[25]}$ who reported that the connective tissue supporting the junctional epithelium is deep connective tissue for nutrition only and so is structurally different from that supporting the oral gingival epithelium which is superficial connective tissue for maturation and nutrition. Even in clinically normal circumstances, it shows an inflammatory cell population such as polymorphonuclear leukocytes and T-lymphocytes. ${ }^{[26]}$ Numerous blood vessels were observed distributed in the underlying connective tissue. This was advocated by Matsuo and Takahashi ${ }^{[27]}$ who found that the entire 
connective tissue of the gingiva in dog was filled with dense network of capillaries and this network was in close proximity to the junctional epithelium and suggested that the blood vessels of the gingiva perform an important function in defending against inflammation.

Concerning the study group, light microscopic examination of the DGJ revealed an orthokeratinized gingival epithelium, non-keratinized sulcular epithelium and junctional epithelium. The orthokeratinized gingival epithelium consisted of stratified squamous epithelium consisting of four distinct layers; basal, prickle, granular and the keratinous layer. The epithelium showed blunt and short epithelial rete pegs. The loose connective tissue papillae are running to a long distance in the gingival epithelium near to the keratinous surface with increase in vascularity. These observations could be in accordance with the results of Domingues et al..$^{[28]}$ who found that the sulcular bleeding index was significantly higher in the test group of women taking oral contraceptives compared to the control group.

Results of the present study showed shifting of the DGJ where both ends of junctional epithelium were located apically to the cementoenamel junction and attached to cementum surface. The sulcular and junctional epithelia showed an increase in their epithelial thickness looking as that of the gingival epithelium. Bundles of collagen fibers in the reticular layer of the lamina propria were observed in the current work but less dense, loosely arranged and not definitely oriented like that in control group. These results are in convenience with Mullally et $a l .{ }^{[29]}$ who concluded that oral contraceptive users had deeper mean probing depth, more severe attachment loss and more sites with bleeding on probing compared to non-users. Consequently, Tilakaratne et al. ${ }^{[30]}$ proved that oral contraceptives increased prevalence of gingivitis and that the attachment loss was significantly higher in females with prolonged usage of hormonal contraceptives, compared with controls.

\section{CONCLUSION}

The use of animal models is often an essential step to provide clear and wide knowledge about the adverse effect of an important widely used drug in our society. The current study showed that oral contraceptives result in marked histological changes on the periodontium which can be correlated to different clinical findings.

\section{ACKNOWLEDGEMENT}

The author would like to express great appreciation for Prof. Fayza El-Daly, Professor of Oral Biology, Alexandria University, for her valuable aid and support throughout this study.

\section{REFERENCES}

1. Chrousos GP. Organization and Integration of the Endocrine System. Sleep Med Clin. 2007; 2(2): 125 - 45.

2. Mascarenhas P, Gapski R, Al-Shammari K, Wang HL. Influence of sex hormones on the periodontium. J Clin Periodontol. 2003; 30(8): $671-81$.

3. Jafri Z, Bhardwaj A, Sawai M, Sultan N. Influence of female sex hormones on periodontium: A case series. J Nat Sc Biol Med. 2015; 6 (Suppl 1): S146 - S149.

4. Mealey L, Moritz J. Hormonal influences on periodontium. Periodontol 2000. 2003; 32: 59-81.

5. Mariotti AJ. Estrogen and extracellular matrix influence human gingival fibroblast proliferation and protein production. J Periodontol. 2005; 76(8): 1391 - 7.

6. Markou E, Eleana B, Lazaros T, Antonios K. The Influence of Sex Steroid Hormones on Gingiva of Women. Open Dent J. 2009; 3: 114 - 9.

7. Krejci CB, Bissada NF. Women's health issues and their relationship to periodontitis. J Am Dent Assoc. 2002; 133: $323-9$.

8. Jonsson D. The biological role of the female sex hormone estrogen in the periodontium-studies on human periodontal ligament cells. Swed Dent J Suppl. 2007; 187: 11-54.

9. Fischer C, Persson E, Persson R. Influence of the menstrual cycle on the oral microbial flora in women: a case-control study including men as control subjects. J Periodontol. 2008; 79(10): $1966-73$. 
10. Yokoyama M, Hinode D, Masuda K, Yoshioka M, Grenier D. Effect of female sex hormones on Campylobacter rectus and human gingival fibroblasts. Oral Microbiol Immunol. 2005; 20: 239 - 43 .

11. Wright KP, Johnson JV. Evaluation of extended and continuous use oral contraceptives. Ther Clin Risk Manag. 2008; 4(5): $905-11$.

12. Tepper NK, Whiteman MK, Zapata LB, Marchbanks PA, Curtis KM. Safety of hormonal contraceptives among women with migraine: A systematic review. Contraception. 2016; 94(6): $630-40$.

13. Tepper NK, Whiteman MK, Marchbanks PA, James AH, Curtis KM. Progestin-only contraception and thromboembolism: A systematic review. Contraception. 2016; 94(6): $678-700$.

14. Haerian-Ardakani A, Moeintaghavi A, Talebi-Ardakani MR, Sohrabi K, Bahmani S, Dargahi M. The association between current low-dose oral contraceptive pills and periodontal health a matched-case-control study. J Contemp Dent Pract. 2010; 11:33 - 40.

15. Saini R, Saini S, Sharma S. Oral contraceptives alter oral health. Ann Saudi Med. 2010; 30 (3):243.

16. Brusca MI, Rosa A, Albaina O, Moragues MD, Verdugo F, Pontón J. The impact of oral contraceptives on women's periodontal health and subgingival occurrence of aggressive periodontopathogens and Candida species. J Periodontol. 2010; 81: $1010-8$.

17. The Development of Science-based Guidelines for Laboratory Animal Care. Proceedings of the November, 2003 International Workshop National Research Council (US) Institute for Laboratory Animal Research. Washington (DC): National Academies Press (US); 2004.

18. Dadaci M, Oztekin C, Oztekin PS, Sargon MF, Ozgur F. Effect of a combined oral contraceptive on patency of arterial anastomosis in a female rat model. Microsurgery. 2015; 35(7): $553-9$.
19. Toryila JE, Amadi K, Odeh SO, Adelaiye AB, Egesie UG, Achiel N. Dynamics of Combined Oral Contraceptive: A Study of Some Haematological Parameters in Female Wistar Rats. IOSR- Journal of Pharmacy; 4(9): 15 - 9.

20. Bashkar SN. Orban's Oral Histology and Embryology: 11th Ed. Baltimore, Boston, Chikago, London, Piladephia, Sydney, Toronto: Mosby st. Louis, 1990. 339 - 41, 349 50, 365, 470-73.

21 Hennet P. Dental anatomy and physiology of small carnivores. In: Crossly \& Penman, ed.: Manual of small animal dentistry. Second edition. BSAVA 1995; 93 - 104.

22. Laugerette F, Gaillard D, Passilly-Degrace P, Niot I, Besnard P. Do we taste fat? Biochimie. 2007; 89(2): 265 - 9.

23. Bartold PM, Walsh LJ, Narayanan AS. Molecular and cell biology of the gingiva. Periodontol 2000. 2000; 24: 28-55.

24. Bosshardt DD, Lang NP. The junctional epithelium: from health to disease. J Dent Res. 2005; 84(1): 9- 20.

25. Nanci A, Bosshardt DD. Structure of periodontal tissues in health and disease. Periodontol 2000. 2006; 40(1): 11 - 28.

26. Schroeder HE, Listgarten MA. The gingival tissues: the architecture of periodontal protection. Periodontol 2000. 1997: 13: 91-120.

27. Matsuo M, Takahashi K. Scanning electron microscopic observation of microvasculature in periodontium. Microsc Res Tech. 2002; 56(1): 3-14.

28. Domingues RS, Ferraz BF, Greghi SL, Rezende ML, Passanezi E, Sant'Ana AC. Influence of combined oral contraceptives on the periodontal condition. J Appl Oral Sci. 2012; 20(2): $253-9$.

29 Mullally BH, Coulter WA, Hutchinson JD, Clarke HA. Current oral contraceptive status and periodontitis in young adults. J Periodontol. 2007; 78(6): 1031 - 6.

30 Tilakaratne A, Soory M, Ranasinghe AW, Corea SM, Ekanayake SL, de Silva M. Effects of hormonal contraceptives on the periodontium, in a population of rural SriLankan women. J Clin Periodontol. 2000; 27(10): 753 - 7. 